\title{
REPRESENTAR E INTERVIR: LINGUAGEM, PRÁTICA DISCURSIVA E PERFORMATIVIDADE*
}

\author{
Décio Rocha** \\ Universidade do Estado do Rio de Janeiro \\ Rio de Janeiro, Brasil \\ CNPq - Conselho Nacional de Desenvolvimento Científico e Tecnológico
}

\begin{abstract}
Resumo: A partir do conceito de prática discursiva (MAINGUENEAU, 1989), visto como a simultânea produção de textos e de uma comunidade, em um encontro marcado por uma relação de reciprocidade na qual uma comunidade produz textos que, por sua vez, garantem visibilidade a essa mesma comunidade, este artigo tem por objetivo explorar o tipo de relação que se estabelece entre linguagem e realidade. Para fins de abordagem de duas notícias da mídia, a análise da natureza performativa das ações relatadas (AUSTIN, 1975) e a explicitação de singularidades do ilocutório (DELEUZE; GUATTARI, 1995) serão dispositivos aos quais se recorrerá para sustentar a tese segundo a qual, antes de representar o mundo, o discurso é uma forma de nele intervir.
\end{abstract}

Palavras-chave: Prática discursiva. Representação e intervenção. Performativo. Ilocucionário. Notícia.

\section{DO DISCURSO À PRÁTICA DISCURSIVA: UM CONCEITO QUE GANHA CORPO}

Este trabalho tem por objetivo propor uma reflexão voltada para o encontro entre linguagem e realidade, explicitando o lugar que reservamos para a performatividade no quadro da perspectiva discursiva que vimos praticando e incluindo nesse debate a singularidade da noção de prática discursiva (MAINGUENEAU, 1989). Dando continuidade a um debate iniciado pelo autor em trabalho anteriormente publicado (cf. ROCHA, 2013), o artigo busca responder a duas questões - complementares, sem dúvida -, a saber: (i) que tipo de relações podemos estabelecer entre a perspectiva discursiva que pretendemos sustentar e a noção de performatividade?; (ii) como dar visibilidade ao conceito de prática discursiva, entendido como reformulante de discurso?

\footnotetext{
* Este artigo é uma releitura de texto publicado em Intersignos, v. 6, n. 1 (2013), versão na qual o córpus, mais restrito, não foi reproduzido na íntegra, o que impediu a compreensão das análises feitas. Na versão atual, além de um córpus expandido e reproduzido em sua totalidade, figuram avanços mais recentes de pesquisa: autores como J. Butler, G. Deleuze e F. Guattari vêm se articular ao quadro teórico de base, reforçando a interseção entre pragmática e perspectiva discursiva; a performatividade passa a ser reconhecida também em nomes substantivos; aprofunda-se a diferença entre performativos e palavras indicativas de ação realizada verbalmente; ganha posição central nas análises o conceito de prática discursiva.

** Professor Associado. Doutor em Linguística Aplicada. Email: rochadm@uol.com.br.
} 
A especificidade da primeira questão prende-se em parte à diversidade de definições que podemos encontrar para o conceito de discurso. Não é propósito meu no momento tematizar tal diversidade e, por essa razão, restrinjo-me a lembrar três definições de discurso dentre as várias que aqui poderiam figurar - definições que representam formas antagônicas de pensar o conceito, se considerarmos a clássica divisão entre tendências anglo-americanas e tendências francesas. Quanto à segunda questão, ela representará um esforço que faço para concretizar um possível modo de atualização da noção de prática discursiva, recorrendo a dispositivos que buscarão dar conta de sua singularidade e de sua produtividade na análise de textos variados.

Inicio, deste modo, lembrando uma definição inaugural de discurso, a saber, a definição oferecida por Z. Harris em Discourse Analysis, obra publicada em 1952. Nela, Harris tematiza duas questões em estreita inter-relação: uma compreensão de discurso entendido como "sucessão de frases", "unidade de análise que ultrapassa o limite da frase", e como o lugar de encontro da língua com a cultura, ou seja, ponto de interseção entre o comportamento linguístico e o não linguístico. Na referida obra do autor, a expressão discourse analysis remete a um método para investigar a coesão de enunciados falados e escritos. Essa primeira definição de discurso fornecida por Harris parece hoje mais compatível com o campo de investigações da Linguística textual, e não da Análise do Discurso.

Muitos dos trabalhos da vertente anglo-americana da Análise do Discurso não se afastarão significativamente dessa primeira concepção de discurso, sendo a ênfase colocada na extensão das unidades de análises (sempre superiores à frase) e no fato de lidarem invariavelmente com enunciados em situação de uso. Alguns autores ainda iluminarão um outro aspecto característico de tal entendimento de discurso, a saber, o caráter interdisciplinar que assumem as pesquisas na área ${ }^{1}$. Acrescentemos, para concluir, que uma outra marca dos estudos realizados nessa vertente é a ênfase no planejamento intencional das trocas verbais por seus atores. No fragmento transcrito a seguir, a diferença estabelecida pelo autor entre texto e discurso explicita essa dimensão consciente de um projeto de comunicação: “Chapter 1, 'Language in use', distinguishes between text (a communicative unit) and discourse (the meaning the text producer intends to communicate and the receiver has to interpret). (WIDDOWSON, 2007).

Passemos a uma outra perspectiva para definir discurso, recuperando, desta vez, a posição defendida ao final dos anos 60 por Michel Pêcheux, filósofo considerado como o fundador da Análise do Discurso na França. Sua orientação teórica se configurou em forte oposição aos trabalhos que se desenvolviam à época sob o marco da Análise de Conteúdo de base behaviorista, americana, em desenvolvimento já desde o início do século $\mathrm{XX}^{2}$.

De modo conciso, diremos que Pêcheux privilegia a articulação entre Linguística, História e Psicanálise para dar conta de fatores como o ideológico e o sujeito na

\footnotetext{
${ }^{1}$ Em seu Discourse Analysis, Brown e Yule (1983) fazem referência a uma interseção entre disciplinas tão diversas quanto a sociolinguística, a psicolinguística, a linguística filosófica e a linguística computacional.

${ }^{2}$ Para um maior detalhamento dos trabalhos em Análise de Conteúdo, ver Rocha e Deusdará (2006).
} 
produção de efeitos de sentido. Aqui, a linguagem mostra-se como não transparente: "é preciso ensinar a ler o real sob a superfície opaca, ambígua e plural do texto" (ORLANDI, 2005, p. 10). Sua concepção de discurso vem desestabilizar o tradicional esquema da comunicação, segundo o qual o emissor transmite uma mensagem a seu receptor, por intermédio de um canal adequado e de um código comum a ambos. Com efeito, distanciando-se de tal perspectiva informacional e problematizando a noção de condições de produção, Pêcheux recusa a ideia de mensagem como transmissão de informação entre A e B; em seu lugar, prefere a noção de discurso como "efeito de sentido" entre A e B (PÊCHEUX, 1969, p. 18). Desde sempre fica claro que A e B não representam "a presença física de organismos humanos individuais", e sim lugares passíveis de uma descrição sociológica (o lugar do patrão, do operário, etc.) que se apresentam alterados em uma série de formações imaginárias referentes à imagem que fazem de si e do outro, assim como do referente (isto é, o contexto ou a situação em que tem lugar o discurso). Estabelecem-se, desse modo, relações entre as situações (que são objetivamente definidas, coincidindo com a realidade física) e as posições (que são representações dessas situações, objetos imaginários) segundo uma lógica particular: o indivíduo interpelado em sujeito pelas formações discursivas (que representam na materialidade linguística as formações ideológicas que lhes correspondem) sustentará processos discursivos, entendidos como "sistema de relações de substituição, paráfrases, sinonímias, etc., que funcionam entre elementos linguísticos - 'significantes' - em uma formação discursiva dada" (PÊCHEUX, 1988, p. 161). Desse modo, o sentido não poderá ser localizado na materialidade do significante, situando-se, antes, na dependência de uma formação discursiva, isto é, segundo a posição sustentada pelo sujeito que enuncia. A dependência de uma formação discursiva com relação ao interdiscurso é, no entanto, dissimulada por intermédio da transparência do sentido que aí se produz, o que confere à forma-sujeito uma propriedade que lhe é constitutiva, a saber, o duplo esquecimento: esquecimento das determinações que lhe designam precisamente o lugar que ele ocupa e o esquecimento de que ele seleciona um enunciado (e não um outro) que já se encontra previsto no campo da formação discursiva considerada (forma de esquecimento que lhe confere a "liberdade" que lhe é possível alcançar).

Como se percebe, a reflexão de Pêcheux se distancia, e bastante, dos critérios utilizados regularmente pela vertente anterior. Sua proposta nada tem a ver com a extensão das unidades de análise ou com qualquer modalidade de sujeito intencional, psicológico, que se revele senhor de seu dizer. O sujeito somente tem acesso a parte de seu dizer. Com efeito, a interpelação do indivíduo em sujeito do ideológico implica o apagamento da língua na história, daí resultando o efeito de evidência do sentido e a ilusão de transparência da linguagem. Essa ilusão também reforça a ilusão de um sujeito-origem do que é dito, dissimulando o fato de que o sujeito se define, antes, como posição, isto é, como lugar do qual lhe é lícito enunciar.

A terceira e última acepção de discurso que apresento é referendada por D. Maingueneau. Em um sentido amplo, discurso designará não tanto um campo de investigação passível de ser circunscrito, mas principalmente um certo modo de apreensão da linguagem, que pressupõe a "atividade de sujeitos inscritos em contextos 
determinados" (MAINGUENEAU, 1998, p. 43). Em uma acepção mais pontual, discurso poderá ser compreendido como um uso mais restrito que se faz do sistema língua, e é sobre essa segunda acepção que incide nosso interesse, tendo em vista sua produtividade no que diz respeito à diversidade de critérios para a constituição de córpus $^{3}$ a serem submetidos à investigação. A título de exemplificação, cito alguns dos critérios que vêm permitindo fracionar - para fins de análise - o universo discursivo, traduzindo-o em domínios ou campos discursivos que já representam uma escolha feita pelo pesquisador: ao se falar de "discurso comunista" ou "discurso socialista", privilegiamos, como critério de classificação, a construção de um certo posicionamento no interior do campo discursivo referente a ideologias políticas, critério esse que já não é o mesmo que nos autoriza a falar de "discurso jornalístico" ou "discurso científico", designações que colocam em cena um certo modo de configuração da ação do homem situada na história. Com base na mencionada diversidade de critérios a serviço de uma tipologização dos discursos, poderemos ainda falar de "discurso do professor" ou de "discurso do operador de telemarketing", quando o enfoque recair sobre uma dada categoria de locutores; e, seguindo a mesma ordem de raciocínio, de "discurso polêmico" ou "discurso prescritivo", quando justamente se desejar enfatizar uma dada função da linguagem.

A produtividade da noção de discurso que acolhemos só se deixa perceber quando nos damos conta de que, seja qual for o critério que adotemos, a apreensão de uma dada identidade discursiva sempre estará na dependência de seu outro, isto é, de uma forma qualquer de alteridade. Em outras palavras, apenas por força de uma estratégia de "facilitação pedagógica" poderão ser dissociadas noções como as de discurso e alteridade, discurso e interdiscurso - entendendo-se por interdiscurso o conjunto das unidades discursivas com as quais um discurso particular entra em relação implícita ou explícita (MAINGUENEAU; CHARAUDEAU, 2004, p. 286). Assim, nessa perspectiva, falar de "discursos comunistas" só ganha sentido quando, no interior de um dado campo, outros tantos "perfis discursivos não comunistas" seriam possíveis ${ }^{4}$, não como mera presença de um real naturalizado, mas precisamente como aquilo que abre a possibilidade de sua constituição como alteridade no plano enunciativo (RODRIGUES; ROCHA, 2010).

A relação que aqui se estabelece entre ato de enunciação e produção textual vem caracterizar a concepção de discurso defendida por Maingueneau. Com efeito, para o autor, discurso (ou prática discursiva) é uma noção que se refere a uma dupla produção que tem lugar simultaneamente: a produção de textos e a produção de uma comunidade discursiva. Dito em outras palavras, a constituição de uma dada comunidade discursiva e a produção textual são as duas faces de uma mesma moeda, não havendo qualquer possibilidade de se estabelecer uma relação de causalidade linear entre ambas. Como se

\footnotetext{
3 Dada a frequência de uso do termo na área dos estudos da linguagem, penso ser adequado contribuir para que córpus (forma única no singular e no plural, a exemplo de "lápis") alcance a condição de palavra da língua portuguesa a ser dicionarizada. Aliás, uma rápida busca da grafia "córpus" no Google acadêmico já nos indica ser essa uma iniciativa apoiada por muitos.

${ }^{4}$ Posição que não é isenta de problemas e que será preciso repensar, se for considerado que "uma série de exclusões intervém na produção de toda estrutura binária, e essas exclusões nunca encontram espaço no discurso racional" (BUTLER, 2005, p. 24).
} 
percebe, o que está em questão, portanto, é a natureza da relação entre os textos e as assim chamadas "condições de produção" desses textos: "os modos de organização dos homens e de seus discursos são indissociáveis, as doutrinas são inseparáveis das instituições que as fazem emergir e que as mantêm". (CHARAUDEAU; MAINGUENEAU, 2004, p. 105).

Como justificar tal concepção de discurso? Devemos lembrar um dos aportes fundamentais da pragmática: a linguagem como forma de ação sobre o mundo. Ora, assim como os homens se organizam em sociedade, trabalham, modificam a ordem das coisas que os rodeiam, eles também produzem linguagem, produzem textos, o que seria uma outra forma de atuar sobre esse mundo. A investigação das interações verbais tem contribuído para reafirmar uma tal perspectiva, na medida em que a palavra desempenha um papel de regulação/construção do vasto leque de relações que se estabelecem entre os homens: relações de dominação, de enfrentamento, de definição de identidades, de produção de diferentes modos de subjetivação.

\section{LINGUAGEM-REPRESENTAÇÃO E LINGUAGEM-INTERVENÇÃO: QUANDO DIZER É INVENTAR}

A concepção de discurso que acolhemos apresenta a vantagem de permitir a relativização do poder da linguagem de representar o mundo para o sujeito. Com efeito, retomando Latour (2001), é preciso superar a crença em uma certa correspondência entre palavras e estados de coisas, ou seja, superar a crença naquilo que fundamenta o que o autor denomina o "acordo modernista", a saber, a ideia de que haveria um mundo "lá fora" ao qual uma mente tentaria obter acesso. (LATOUR, 2001, p. 133).

$\mathrm{Na}$ verdade, a novidade inaugurada nesse debate reside na possibilidade de perceber que aí temos um desafio que em muito ultrapassa as fronteiras da Linguística, tal como esta se definiu ao início do século XX. Entramos, por essa via, no debate relativo à articulação entre linguagem e cognição.

Tendo definido discurso como prática discursiva (MAINGUENEAU, 1989), definição que pressupõe, como vimos, uma "reversibilidade essencial entre as duas faces, social e textual, do discurso" (MAINGUENEAU, 1989, p. 56), devemos afastar como inadequada qualquer interpretação que reduza o conceito à mera sequência de palavras ou a um "contraponto do mundo empírico". Afinal, não estamos diante de uma polarização entre "mundo real" e "palavras e textos": palavras também são produção do mundo, o que já se verifica desde o exemplo dos filósofos analíticos da linguagem dos anos 60, quando, com Austin, se afirma a noção de performatividade da linguagem. Afinal, fazemos coisas quando produzimos textos: ao dizer "obrigado", realizo a ação de agradecer algo; ao dizer "prometo te trazer o livro", engajo-me efetivamente numa promessa, tornando-me "devedor" de alguém.

\footnotetext{
5 Aliás, não foi por outra razão que o autor preferiu a denominação "prática discursiva" a "discurso": para evitar a clássica confusão entre discurso e texto.
} 
Se discurso é tudo isso - simultaneamente produção textual e produção de uma comunidade -, então, não é possível supor que ele mantenha uma relação de mera representação com o mundo: o discurso não pode simplesmente representá-lo porque ele não está distanciado do mundo, ou seja, ele também participa desse mundo. Seria, talvez, preferível assumir que a linguagem tem, sim, algum poder de representação, mas o mundo já não coincidiria exatamente com a representação desse mundo por intermédio da linguagem, uma vez que, ao fazer referência a esse mundo, a linguagem congela o tempo, altera distâncias, oferecendo-nos um retrato - sempre parcial - de um dado momento, o retrato de uma realidade passada e/ou de uma nova paisagem que não coincide com as coordenadas geográficas de tudo o que pode ser verificado no "mundo ao vivo". Lembro que evidências como essas se aproximam da posição assumida pelo biólogo Francisco Varela, que, rejeitando uma dimensão ontológica do conceito de representação (isto é, recusando o conceito em seu sentido forte, segundo o qual o mundo tem uma existência que antecede o momento de seu conhecimento) aceita, contudo, uma acepção fraca (ou pragmática) do conceito, segundo a qual a representação do mundo remete a uma construção ou interpretação desse mundo sempre temporária e aberta a problematizações. Em outras palavras, uma atividade de representação que compreende em sua atualização um processo de invenção (VARELA; THOMPSON; ROSCH, 2003, p. 144). É precisamente a essa dimensão de invenção que chamei em outros trabalhos, seguindo a lição deixada por Deleuze e Guattari (1995), de "intervenção no mundo": os enunciados só representam o mundo no sentido de produzirem uma certa versão desse mundo, ou seja, de intervirem nesse mundo (ROCHA, 2006).

\section{NOTÍCIAS QUE TEMATIZAM O QUE PODE UMA PALAVRA}

Quero tematizar a relação (problemática) entre discurso e representação, recuperando a noção de prática discursiva (MAINGUENEAU, 1989) para proceder a uma leitura que considero relevante de textos que circulam na mídia. Pretendo com isso retomar um debate voltado para os estudos da performatividade da palavra, conferindo, segundo espero, uma maior concretude ao conceito de prática discursiva.

Tendo por meta o que ora anuncio, convido o leitor a tomar conhecimento dos textos que figuram em anexo, versando sobre o episódico movimento Cansei, nome pelo qual ficou conhecido popularmente o Movimento Cívico pelo Direito dos Brasileiros $^{6}$. No anexo 1 , reproduzimos uma notícia publicada no caderno O País do jornal $O$ Globo de 17/08/2007, intitulada "Governador do Piauí protesta contra declarações do presidente da Phillips". Muito resumidamente, trata-se da reação de descontentamento manifestada pelo governador do Piauí diante de declaração prestada por Paulo Zottolo, presidente da Philips, ao jornal Valor Econômico: apoiando o movimento Cansei e desejando "remexer no marasmo cívico do Brasil", Zottolo

\footnotetext{
${ }^{6}$ Trata-se de movimento surgido em julho de 2007, logo após o acidente com o voo 3054 da TAM. O Cansei se declarava apartidário e tinha por objetivo a reflexão sobre os motivos do que considera a desordem da administração pública no governo Lula. Intelectuais de esquerda apontaram o movimento como elitista.
} 
afirmou que "não se pode pensar que o país é um Piauí, no sentido de que tanto faz quanto tanto fez. Se o Piauí deixar de existir ninguém vai ficar chateado". Quanto ao anexo 2, intitulado "Episódio do preconceito ao Piauí", trata-se de fragmento de um texto maior localizado na internet que tematiza o movimento Cansei, caracterizando-o em seus traços gerais.

Sobre que fato(s) exatamente se fala nessas notícias? Se tomarmos o exemplo da primeira delas, reproduzida no anexo 1, veremos que se trata, na realidade, de algo que já se anuncia no título e no subtítulo: alguém declara algo, e essa declaração gera reações de protesto. Eis o que aqui se anuncia como acontecimento: duas ações que se realizam exclusivamente pela linguagem, a saber, as ações de declarar algo e protestar contra algo dito. Aliás, ambas remetem a um tipo de ação que parece ser a tônica de todo o texto, como se verifica ao se recuperar tudo o que é dito na notícia:

(1) o presidente da Philips apoia o movimento "Cansei";

(2) o presidente da Philips concede entrevista ao jornal "Valor Econômico";

(3) o presidente da Philips debocha do Piauí em sua declaração;

(4) o governador do Piaú protesta em uma nota contra o "deboche" do presidente da Philips;

(5) o governador cobrará em ofício posicionamento do presidente Lula e do Congresso;

(6) o presidente da Philips desculpa-se por telefone com o governador do Piauí;

(7) o governador aceita as desculpas;

(8) o governador solicita retratação pública;

(9) o presidente da Philips promete desculpar-se em nota a ser divulgada;

(10) um site piauiense propõe campanha de boicote aos produtos da Philips;

(11) o site piauiense alega algo como justificativa de sua proposta;

(12) o presidente da Philips não consideraria importante o mercado piauiense.

Listando-se as doze ações que constituem a notícia veiculada, algo se percebe em comum: todas se caracterizam ou como performativas, ou como ações cuja realização remete a um ato de natureza verbal. Com efeito, ações como declarar, protestar, desculpar-se, aceitar desculpas, pedir retratação pública, prometer retratar-se, alegar possuem em comum o fato de realizarem um ato pelo simples fato de serem enunciadas; por sua vez, apoiar movimento cívico contra o governo, entrevistar, conceder entrevista, debochar, redigir ofício, cobrar posicionamento, propor campanha de boicote são ações que se concretizam por intermédio do uso da palavra.

Se passamos agora a um outro fragmento de texto também veiculado pela mídia na mesma ocasião (anexo 2), poderemos ainda ter acesso a uma série de outras ações cujo denominador comum permanecerá sendo esse mesmo caráter verbal das ações realizadas. Vejamos:

(13) o presidente da Philips no Brasil concede entrevista ao jornal Valor Econômico;

(14) o presidente da Philips afirma que, ao apoiar o movimento Cansei, deseja remexer no "marasmo cívico" do Brasil; 
(15) o presidente da Philips afirma que "não se pode pensar que o país é um Piauí, no sentido de que tanto faz quanto tanto fez. Se o Piauí deixar de existir ninguém vai ficar chateado";

(16) o presidente da Philips pede desculpas ao povo do Piauí em entrevista à Folha de $S$. Paulo;

(17) o presidente da Philips diz que seu comentário foi "infeliz";

(18) o presidente da Philips se desculpa por "deboche" sobre o Piauí;

(19) o presidente da Philips diz ao governador Wellington Dias ( $\mathrm{PT}$ ) que visitará o Piauí;

(20) divulga-se para a imprensa uma informação: a visita o presidente da Philips ao Piauí;

(21) estudantes quebram dois aparelhos da Philips durante manifestação pública em uma praça de Teresina;

(22) na manifestação, é distribuída uma nota de repúdio ao presidente da Philips;

(23) na nota, diz-se que a afirmação do presidente da Philips foi uma "demonstração clara do preconceito que a elite paulistana tem contra nordestinos";

(24) UNE e UBES também assinam a nota de repúdio;

(25) a Assembléia Legislativa do Piauí aprova um decreto considerando o presidente da Philips persona non grata no estado;

(26) a pressão pública faz com que o decreto seja aprovado;

(27) o título de persona non grata impede que qualquer instituição do poder público no Piauí conceda homenagens ao presidente da Philips;

(28) as declarações do presidente da Philips também repercutem na Assembléia Legislativa do Ceará;

(29) o deputado Tomás Figueiredo Filho (PSDB) propõe uma moção de repúdio contra o presidente da Philips;

(30) o deputado Yala Sena diz que "somos Estados nordestinos e estamos cansados é dessa discriminação".

Assim como era o caso do texto anterior, diversos performativos são localizados neste segundo texto, o que vem ratificar a compreensão de que se trata de mais uma notícia em que a palavra coincide com a ação realizada. Se se perguntasse o que acontece neste segundo texto, seria possível responder que acontecem ações que se realizam por intermédio da palavra, a exemplo de ações como pedir desculpas / desculpar-se, dizer, divulgar, propor, que são inequivocamente performativos.

Para além desses performativos explícitos, ainda se encontram ações cuja realização remete a algo que, no contexto, somente poderá ocorrer por intermédio da palavra. Explico-me. A ação de apoiar algo pode ser executada por intermédio de um gesto físico, em casos como, por exemplo, "ele apoiou a mão sobre a mesa". No entanto, sua natureza verbal é evidente em "ele apoiou o movimento Cansei". O mesmo parece ocorrer com enunciados em que se apresentam sintagmas como os seguintes: conceder entrevista, remexer no "marasmo cívico", assinar nota, aprovar decreto, conceder homenagem, impedir que se conceda homenagem - todas elas ações que, no contexto em que figuram, só podem se realizar por um ato verbal.

Até aqui, ratifica-se o já conhecido no texto do anexo 1, em que a linguagem não pode ser considerada como cumprindo a função de proceder a mero relato de algo anteriormente ocorrido, caracterizando-se, antes, como a própria ação que se realiza. Com efeito, se algo acontece no texto 1, é sempre algo que remete a uma ação da palavra sobre o mundo: debochar de alguém, declarar algo, desculpar-se, alegar algo, etc. 
Contrariando essa onipresença de ações que se atualizam pela palavra, quero aqui retomar duas últimas ações que, ao que tudo parece indicar, realizam-se por um gesto físico de natureza não verbal: (20) o presidente da Philips visitará o Piauí; (21) estudantes quebraram dois aparelhos da Philips. Como se percebe, visitar uma cidade ou quebrar aparelhos são ações que se praticam agindo-se diretamente sobre o mundo circundante, por meio de um deslocamento físico no espaço para visualizar algo (visitar um local), ou de uma determinada força que se aplica sobre um objeto de modo a danificá-lo (quebrar algo). Contudo, parece que, mesmo nesses casos, a dimensão verbal não foi suprimida: ainda que seja bastante plausível perceber nessas duas ações sua natureza, digamos, não linguageira, é preciso reconhecer que ambas se atualizam - e se legitimam - em um contexto eminentemente verbal. Com efeito, a visita ao Piauí se anuncia em um contexto que remete a um pedido de desculpas por parte do presidente da Philips; o mesmo se dá em relação ao ato de quebrar aparelhos da Philips, que tem lugar em meio a uma manifestação pública de repúdio ao que declarara o presidente da empresa sobre o Piauí. Logo, ambas as ações podem ser consideradas como emblemáticas de um gesto maior - de desculpas ou de acusação - que ganha sentido apenas por intermédio da linguagem, explicitando-se, desse modo, o ilocutório, que remete àquilo que se faz quando se fala: "o ilocutório, por sua vez, é explicado por agenciamentos coletivos de enunciação, por atos jurídicos, equivalentes de atos jurídicos, que coordenam os processos de subjetivação ou as atribuições de sujeitos na língua, e que não dependem nem um pouco dela." (DELEUZE; GUATTARI, 1995, p. 16)

Quero ainda registrar uma outra singularidade do texto do anexo 2 no que diz respeito à natureza linguageira das ações que se praticam: para além dos verbos, substantivos como comentário, deboche, informação, manifestação pública, nota de repúdio, afirmação, decreto, pressão pública, declaração, moção de repúdio, discriminação, mantêm preservados os traços de uma certa categoria de eventos que se atualizam na (e pela) linguagem.

Diante da significativa presença de tal categoria de acontecimentos na notícia acontecimentos de natureza discursiva, que recuperamos na superfície dos textos por meio de verbos e nomes -, não nos resta senão reconhecer que a função da linguagem aqui não pode ser propriamente representar uma certa conformação de mundo, isto é, "contar" o que acontece no mundo, como se primeiramente se produzisse uma ação (não linguageira) qualquer que apenas mais tarde seria reportada por meio das palavras; antes, sua função parece coincidir com a própria produção e invenção desse mundo, uma vez que tudo o que ocorre são ... proferimentos de acusação, de indignação, de retratação, de proposição, etc.

Para finalizar este breve exercício de análise, quero observar que a referida produção/invenção de uma determinada configuração de mundo pressupõe necessariamente um certo arranjo ou uma certa qualidade de relações entre os sujeitos que dele participam, instituindo-se, desse modo, alianças e oposições em meio à polêmica criada. Não é outra coisa o que encontramos quando deparamos com notícias como as que compõem esse córpus: pistas para trabalhar os embates e as alianças que se 
travam ininterruptamente. É o que se atesta ao se reler o texto do anexo 1, por exemplo, no qual podemos identificar sucessivos estágios de alianças e de afrontamentos ${ }^{7}$ :

\author{
Movimento "Cansei" x governo Lula \\ Presidente da Philips + movimento "Cansei" x governo Lula \\ Jornal "Valor Econômico" + presidente da Philips \\ Governador do Piauí + piauienses x presidente da Philips \\ Governador do Piauí + presidente Lula + Congresso \\ Presidente Lula + Congresso x presidente da Philips \\ Presidente da Philips + governador do Piauí \\ Presidente da Philips + piauienses \\ Piauienses x presidente da Philips
}

Tais alianças e oposições entre diferentes agentes são a contrapartida do estado de coisas criado por todo o conjunto de ações (de natureza verbal) exercidas nesse universo. Ora, a esse respeito, o córpus sobre / com o qual trabalhamos oferece-nos um caminho bastante seguro como acesso a uma noção que considero central na perspectiva discursiva de Maingueneau: a noção de prática discursiva. Como já definida anteriormente, a prática discursiva traduz a indissociabilidade constitutiva que se verifica entre uma dada produção de textos e a constituição de grupos que, por um lado, produzem esses textos e, por outro, são a seu turno também por eles produzidos. Como vemos, uma breve leitura da notícia do anexo 1 é capaz de nos oferecer o que denominamos "pistas para trabalhar embates e alianças". Se estendêssemos nosso córpus, incorporando outros textos publicados na ocasião pela mídia ${ }^{8}$, teríamos ainda acesso a outras tantas informações que só fariam alargar esse círculo de alianças e afrontamentos: como aliados do presidente da Philips e do movimento Cansei incluiríamos a Ordem dos Advogados de São Paulo, Distrito Federal e Mato Grosso do Sul, o Conselho Regional de Medicina, a FIESP, a Associação Brasileira de Odontologia, artistas (Regina Duarte, Hebe Camargo, Ivete Sangalo, Léo Jaime, dentre outros), etc.

A partir das referidas pistas, dois procedimentos poderiam, então, ser adotados: (i) produção de um novo córpus constituído não mais por textos da mídia versando sobre o movimento Cansei, mas por textos em que os próprios participantes dessa rede de alianças e embates tomassem a palavra, a exemplo da entrevista concedida pelo presidente da Philips à Folha de S. Paulo, de depoimentos prestados por atores diversos, etc.; (ii) levantamento de hipóteses acerca do modo como se constituem tais redes, traçando-se um breve perfil das comunidades que, no contexto da noção de prática discursiva segundo formulação de Maingueneau, são a contrapartida daquela produção textual $^{9}$.

\footnotetext{
${ }^{7}$ Nos enunciados que se seguem, o sinal x indica uma relação de oposição; o sinal + , uma relação de aliança.

${ }^{8}$ Por exemplo, buscar nas referências a menção ao MOVIMENTO Cívico pelo Direito dos brasileiros, documento do qual foi extraído o anexo 2.

${ }^{9}$ Penso que a decisão de trabalhar com textos enunciados pelos próprios atores que constituem a rede de alianças e afrontamentos traria maior legitimidade a uma investigação interessada pelo conceito de prática discursiva.
} 
O que ora se verifica é que (quase) nada acontece no mundo relatado nessas notícias que não passe pela palavra. É pela palavra que se atualizam as ações e, por isso, a palavra é o agente mesmo que intervém, que modifica, que produz e altera relações no mundo apresentado.

\section{4 (IN)CONCLUSÕES: A LINGUAGEM COMO TRANSMISSÃO DE PALAVRAS DE ORDEM ${ }^{10}$}

Como vimos, ao se rejeitar a versão forte de representação, rejeita-se, por extensão, um certo entendimento de cognição vista como mera recognição, que consiste no "exercício concordante de todas as faculdades sobre um objeto suposto como sendo o mesmo: é o mesmo objeto que pode ser visto, tocado, lembrado, imaginado, concebido" (KASTRUP, 1999).

Já ao se relacionar linguagem e representação na acepção fraca da palavra, assegura-se uma dimensão produtiva de coengendramentos do sujeito e do mundo por intermédio da palavra. A linguagem não seria mero instrumento à disposição de uma mente para re(a)presentação de um mundo "lá fora" à espera de ser descoberto, garantindo-se, desse modo, uma boa dose de invenção nessa nova modalidade de representação. Linguagem para além da informação e da comunicação, funcionando a palavra que se enuncia como palavra de ordem.

Concluo este artigo refletindo sobre por que opto por uma perspectiva discursiva de base enunciativa e por que pretendo reservar um lugar de destaque para a noção de prática discursiva. De modo conciso, trabalhar numa perspectiva enunciativa, assumindo um compromisso com a alteridade, com o heterogêneo, contribui no sentido de fazer implodirem as visões totalizantes sobre o real, possibilitando repensar os grandes estereótipos com os quais convivemos; contribui também no sentido de desnaturalizar o que pode efetivamente ser apreendido como efeito discursivo, em posição plenamente compatível com uma visão performativa da linguagem, entendida como "essa dimensão do discurso que tem a capacidade de produzir o que ele nomeia". (BUTLER, 2005, p. 17)

Refletir sobre tais questões implica, sem dúvida, um compromisso social que nos reenvia à definição de uma ética do profissional interessado pelo campo da linguagem. Implica também a construção de um caminho a ser percorrido pelo analista do discurso para proceder à sua leitura de um dado entorno social, leitura essa autorizada em grande parte pelo recurso à noção de prática discursiva, uma vez que é ela que nos permite fazer hipóteses acerca do modo como textos e grupos se interdelimitam. Eis aí uma tarefa inadiável nos dias de hoje, quando tanto se fala em subjetividades não identitárias, mas nunca para retraçar um caminho de desnaturalização dessas identidades, explicitando, assim, o processo de sua produção em práticas de diversas ordens - linguageiras ou outras. E se dizemos tratar-se de uma tarefa inadiável, é porque ela apenas reforça o compromisso ético acima referido.

\footnotetext{
${ }^{10}$ Por palavra de ordem entendo "a relação de qualquer palavra ou de qualquer enunciado ... com atos de fala que se realizam no enunciado, e que podem se realizar apenas nele". (DELEUZE; GUATTARI, 1995, p. 16)
} 
AUSTIN, J. L. How to do things with words. Cambridge, Massachusetts: Harvard University Press, 1975. BUTLER, J. Humain, inhumain. Le travail critique des normes - Entretiens. Trad. de Jérôme Vidal e Christine Vivier. Paris: Ed. Amsterdam, 2005.

CharaudeaU, P.; MAINGUENEAU, D. Dicionário de Análise do Discurso. São Paulo: Contexto, 2004.

DELEUZE, G.; GUATTARI, F. 20 de novembro de 1923. Postulados da Linguística. In: . Mil Platôs Capitalismo e Esquizofrenia, vol. 2. Trad.: Ana Lúcia de Oliveira e Lúcia Cláudia Leão. São Paulo: Ed. 34, 1995.

HARRIS, Z. Discourse Analysis. In: Language, v. 28, n. 1, p. 1-30. Washington: Linguistic Society of America, 1952.

KASTRUP, V. A invenção de si e do mundo. Campinas, SP: Papirus, 1999.

LATOUR, B. A esperança de Pandora: ensaios sobre a realidade dos estudos científicos. Bauru, SP: EDUSC, 2001.

MAINGUENEAU, D. Novas tendências em Análise do Discurso. Campinas, SP: Pontes, 1989.

Termos-chave da Análise do Discurso. Belo Horizonte: Ed. UFMG, 1998.

MOVIMENTO Cívico pelo Direito dos Brasileiros. Disponível em: <artigos.tol.pro.br/portal/linguagempt/Movimento\%20C\%C3\%ADvico\%20pelo\%2 Direito\%20dos\%20Brasileiros $>$. Acesso em: 20 nov. 2013.

ORLANDI, E. P. Análise de Discurso - princípios \& procedimentos. Campinas, SP: Pontes, 1999 9-13,2005.

Michel Pêcheux e a Análise do Discurso. Estudos da Lingua(gem), Vitória da Conquista, n. 1, p.

PÊCHEUX, M. Analyse Automatique du Discours. Paris: Dunod, 1969.

Semântica e Discurso - uma crítica à afirmação do óbvio. Campinas: Ed. da Unicamp, 1988.

ROCHA, D. Representação e intervenção: produção de subjetividade na linguagem. Gragoatá. Niterói: Ed. UFF, v. 21, p. 355-372, 2006.

Circunscrevendo um caminho em análise do discurso: linguagem-representação e linguagemintervenção. Intersignos, Rio de Janeiro, v. 6, n. 1, p. 67-82, jun. 2013.

; DEUSDARÁ, B. Análise de conteúdo e Análise do discurso: o linguístico e seu entorno. $\overline{D E L T A}$, São Paulo, v. 22, n.1, p. 29-52, 2006.

RODRIGUES, I.; ROCHA, D. Implicações de uma perspectiva discursiva para a construção de uma metodologia de análise das práticas linguageiras. Gragoatá (UFF), v. 29, p. 205-222, 2010.

VARELA, F.; THOMPSON, E.; ROSCH, E. A mente incorporada: Ciências cognitivas e experiência humana. Porto Alegre, RS: Artmed, 2003.

WIDDOWSON, H.G. Discourse Analysis. Oxford: Oxford University Press, 2007. 


\section{Governador do Piauí protesta contra declarações do presidente da Phillips}

Executivo dissera que se 'Piauí deixar de existir, ninguém vai ficar chateado'

\section{$\frac{\text { Efrém Ribeiro }}{\text { Especial para O GLOBO }}$}

- TERESINA. O governador do Piauí, Wellington Dias (PT), divulgou nota ontem protestando contra uma declaração do presidente da Philips, Paulo Zottolo, um dos integrantes do movimento "Cansei", que considerou ofensiva a seu estado. Em entrevista ao jornal "Valor Econômico", Zottolo disse que, ao apoiar o "Cansei", desejava mexer no "marasmo cívico" do Brasil, e afirmou: "Não se pode pensar que o país é um Piauí, no sentido de que tanto faz quanto tanto fez. Se o Piauí deixar de existir, ninguém vai ficar chateado".

Dias disse ontem que enviará ao presidente Lula e ao Congresso um ofício para que o governo e o Parlamento se posicionem quanto ao que considera "um deboche". Na nota, o governador diz que "lamentavelmente, o presidente da Phillips

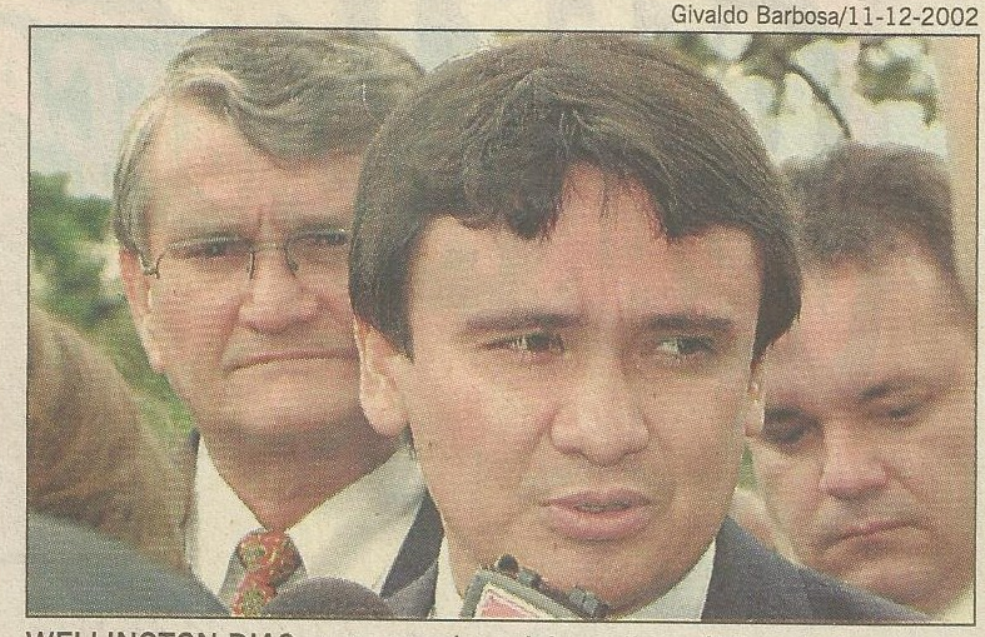

WELLINGTON DIAS: o governador exigiu pedido público de desculpas

desconhece o Piauí" e pede que Deus dê a Zottolo a oportunidade de conhecer o estado.

À tarde, Zottolo ligou para Dias, disse que não foi intenção dele ofender e pediu desculpas. $\mathrm{O}$ governador aceitou, mas pediu que a retratação fosse pública. Zottolo informou a Dias que divulgará nota pedindo desculpas ao Piauí e aos piauienses.
As declarações causaram grande repercussão no Piauí. Um site de notícias, o "Portal Meio Norte", de Teresina, propôs uma campanha de boicote dos piauienses aos produtos da Philips, alegando que, pelo raciocínio de Zottolo, o Piauí não é um mercado importante para a economia e para o faturamento da empresa.

ANEXO 2

\section{Episódio do preconceito ao Piauí}

Em entrevista ao jornal Valor Econômico, o presidente da Philips no Brasil, Paulo Zottolo afirmou que, ao apoiar o movimento Cansei, desejava remexer no "marasmo cívico" do Brasil, e afirmou: "Não se pode pensar que o país é um Piauí, no sentido de que tanto faz quanto tanto fez. Se o Piauí deixar de existir ninguém vai ficar chateado". Mais tarde, 
Zottolo pediu desculpas ao povo do Piaú em entrevista a Folha de S. Paulo, dizendo que seu comentário foi "infeliz". Mônica Bergamo.

"Presidente da Philips se desculpa por "deboche" sobre o Piauí". Folha de S. Paulo. 16 de agosto de 2007. Acessado em 6 de outubro de 2007. No dia 17 de agosto, Zottolo disse ao governador Wellington Dias (PT) que visitaria o Piauí. Após divulgada tal informação para a imprensa, estudantes quebraram dois aparelhos da Philips durante manifestação pública em uma praça de Teresina. Cerca de 50 manifestantes estavam presentes e uma nota de repúdio a Zottolo foi distribuída. Um trecho do texto, assinado por entidades como UNE e $U B E S$, diz que a afirmação do presidente da Philips foi uma "demonstração clara do preconceito que a elite paulistana tem contra nordestinos."José Eduardo Rondon e Simone Iglesias.

"Estudantes do Piauí fazem ato contra Philips; "Cansei" critica o governo no Sul". Folha de S. Paulo. 18 de agosto de 2007. Acessado em 6 de outubro de 2007.Devido à pressão pública, a Assembléia Legislativa do Piauí aprovou um decreto considerando Zottolo persona non grata no estado. O título é apenas simbólico, mas impede que qualquer instituição do poder público no Piaú conceda homenagens a Zottolo. As declarações de Zottolo também repercutiram na Assembléia Legislativa do Ceará. O deputado Tomás Figueiredo Filho $(P S D B)$, propôs uma moção de repúdio contra o presidente da Philips. "Somos Estados nordestinos e estamos cansados é dessa discriminação", disse o deputado Yala Sena.

Fonte: <artigos.tol.pro.br/portal/linguagem-

pt/Movimento\%20C\%C3\%ADvico\%20pelo\%20Direito\%20 dos\%20Brasileiros $>$

Recebido em: 02/12/13. Aprovado em: 21/10/14.

Title: Representing and intervening: language, discursive practice and performativity Author: Décio Rocha

Abstract: Based on the concept of discursive practice (MAINGUENEAU, 1989), which sees it as the simultaneous production of texts and of a community in a reciprocal relationship in which that community produces texts that in turn give visibility to it, this paper explores a key point of contact between language and reality. In order to approach two media news, the analysis of the performative nature of reported actions (AUSTIN, 1975) and the explicitation of singularities of the illocutionary (DELEUZE; GUATTARI, 1995) will be a device to argue that, before representing the world, speech is a way of intervening in it.

Keywords: Discursive practice. Representation and intervention. Performative. Illocutionary. News.

Título: Representar e intervenir: lenguaje, práctica discursiva y performatividad

Autor: Décio Rocha

Resumen: Desde el concepto de práctica discursiva (MAINGUENEAU, 1989), visto como la producción simultánea de textos y de una comunidad en un encuentro marcado por una relación de reciprocidad en la cual una comunidad produce textos que, a su vez, garantizan visibilidad a esa misma comunidad, este artículo tiene por objetivo explorar el tipo de relación que se establece entre lenguaje y realidad. Para fines de abordaje de dos noticias de medios de comunicación, el análisis de la naturaleza performativa de las acciones relatadas (AUSTIN, 1975) y la explicitación de singularidades del ilocucionario (DELEUZE; GUATTARI, 1995) serán dispositivos a los cuales se recorrerá para sostener la tesis segundo la cual, antes de representar el mundo, el discurso es una manera de en ello intervenir.

Palabras-clave: Práctica discursiva. Representación e intervención. Performativo. Ilocucionario. Noticia. 